\title{
Polycystic ovary syndrome and risk of endometrial, ovarian, and breast cancer: a systematic review
}

Holly R. Harris ${ }^{1,2^{*}}$ and Kathryn L. Terry ${ }^{2,3}$

\begin{abstract}
Background: Polycystic ovary syndrome (PCOS) is a complex endocrine disorder with an estimated prevalence of $4-21 \%$ in reproductive aged women. The altered metabolic and hormonal environment among women with PCOS may increase their risk of some types of cancer.

Methods: We performed a comprehensive review of the literature using numerous search terms for all studies examining the associations between polycystic ovary syndrome and related characteristics and cancer published in English through October 2016. This review summarizes the epidemiological findings on the associations between PCOS and endometrial, ovarian, and breast cancers and discusses the methodological issues, complexities, and underlying mechanisms of these associations.

Results: We identified 11 individual studies and 3 meta-analyses on the associations between PCOS and endometrial cancer, 8 studies and 1 meta-analysis for ovarian cancer, and 10 studies and 1 meta-analysis for breast cancer. Multiple studies reported that women with PCOS were at a higher risk for endometrial cancer; however, many did not take into account body mass index (BMI), a strong and well-established risk factor for endometrial cancer. The association with ovarian cancer was less clear, but a potentially increased risk of the borderline serous subtype was reported by two studies. No consistent association between PCOS risk and breast cancer was observed.

Conclusion: The associations between PCOS and endometrial, ovarian, and breast cancer are complex, with the need to consider many methodological issues in future analyses. Larger well-designed studies, or pooled analyses, may help clarify these complex associations.
\end{abstract}

Keywords: Polycystic ovary syndrome, Endometrial cancer, Ovarian cancer, Breast cancer

\section{Background}

Polycystic ovary syndrome (PCOS) is a complex endocrine disorder characterized by oligomenorrhea, hyperandrogenism, and polycystic ovaries. It has an estimated prevalence of $4-21 \%$ in reproductive aged women depending on the diagnostic criteria and population examined [1-7]. In the U.S. it has been estimated that 5 million women may have PCOS [8]. PCOS is associated with metabolic abnormalities including dyslipidemia,

\footnotetext{
* Correspondence: hharris@fredhutch.org

'Program in Epidemiology, Division of Public Health Sciences, Fred Hutchinson Cancer Research Center, M4-859 Seattle, WA, USA

${ }^{2}$ Department of Obstetrics and Gynecology, Brigham and Women's Hospital and Harvard Medical School, Boston, MA, USA

Full list of author information is available at the end of the article
}

insulin resistance, and type II diabetes and is also one of the most common causes of reduced fertility $[9,10]$. The altered metabolic and hormonal environment among women with PCOS may increase their risk of some types of cancer.

First described by Stein and Leventhal in 1935 as women with polycystic ovaries, amenorrhea, and hirsutism [11], PCOS is currently clinically identified by one of three diagnostic criteria set by the National Institutes of Health/National Institute of Child Health and Human Disease (NIH/NICHD),[12] European Society for Human Reproduction and Embryology/ American Society for Reproductive Medicine (ESHRE/ ASRM) (Rotterdam criteria),[13] and Androgen Excess and PCOS Society [14]. While the definitions are 
similar with regard to assessment of menstrual history and androgen excess (defined by clinical characteristics or serum androgen levels) they differ in that the $\mathrm{NIH}$ definition does not consider ovarian morphology (Table 1). Thus, the prevalence of PCOS varies depending on the diagnostic criteria used with the $\mathrm{NIH} / \mathrm{NICHD}$ criteria resulting in the lowest prevalence estimates followed by the Androgen Excess Society and ESHRE/ASRM [3].

The clinical presentation of PCOS varies but commonly includes ovulatory dysfunction (oligomenorrhea, irregular periods and/or anovulatory cycles), hirsutism, acne, and polycystic ovaries (PCO). Women with PCOS commonly have insulin resistance and metabolic syndrome [15-19]. In addition, they are also at increased risk of type II diabetes,[20, 21] high cholesterol,[22-25], high blood pressure,[26-28] and are more likely to be overweight or obese [29-31]. Pharmacological agents are the first- and second-line treatments for many PCOS symptoms including: oral contraceptive use for oligomenorrhea, hirsutism, and acne; metformin for anovulatory infertility, oligomenorrhea, and type II diabetes prevention and treatment; and ovulation induction drugs (clomiphene and letrozole) for anovulatory infertility in this population [32].

\section{Epidemiologic evidence \\ Endometrial cancer}

An association between PCOS and endometrial cancer was first suggested over fifty years ago by a series of small case reports, but these studies were limited by lack of control groups and small numbers [33]. Three metaanalyses, with overlapping studies, have reported a significant increased risk of endometrial cancer among women with PCOS (Table 2) [34-36]. However, they each included estimates from analyses that did not take into account BMI which is a common characteristic of PCOS and a strong and well-established risk factor for endometrial cancer [37, 38].

Five studies have examined the association between PCOS and endometrial cancer without accounting for BMI (Table 2). Two of these were registry-based cohorts reporting estimates of 3.9 (95\% confidence interval [95\% $\mathrm{CI}]=2.2-6.3) \quad[39]$ and $4.7(95 \% \mathrm{CI}=1.6-14.1)$. Three case-control studies reported odds ratios (ORs) of 5.4 (95\% CI $=2.4-12.3),[40] 8.9$ (95\% CI $=0.43-184.86),[41]$ and $9.0(95 \% \mathrm{CI}=0.5-176.1) \quad[42]$. In addition, two studies examining chronic anovulation syndrome and androgen excess/menstrual disorders as proxies for PCOS, reported ORs of $3.1(95 \% \mathrm{CI}=1.1-7.3)$ [43] and $2.0(95 \% \mathrm{CI}=1.1-3.3),[44]$ respectively, while a study examining polycystic ovarian morphology reported no association ( $\mathrm{OR}=1.0 ; 95 \% \mathrm{CI}=0.4-2.7)$ [45]. Besides lack of adjustment for BMI these studies were additionally limited by a small number of exposed cases, consisting of 16 or fewer cases with PCOS. In studies that have reported effect estimates adjusted for BMI the observed associations with PCOS and endometrial cancer have been less consistent [46-48]. Wild et al. followed a cohort of women diagnosed with PCOS and reported an increased risk of endometrial cancer in these women compared to age-matched controls with OR of 5.3 (95\% $\mathrm{CI}=1.5-18.6)$ without adjustment for BMI and 6.1 (95\% $\mathrm{CI}=1.0-36.9)$ after adjustment for BMI [47]. In contrast, Fearnley et al. reported an attenuation of the OR following adjustment for $\mathrm{BMI}(\mathrm{OR}=4.0 ; 95 \% \mathrm{CI}=1.7-9.3$ and $\mathrm{OR}=2.2 ; 95 \% \mathrm{CI}=0.9-5.7$, respectively) [46]. Finally, Zucchetto et al. observed no association between PCOS and endometrial cancer with a BMI-adjusted OR of 1.3 $(95 \% \mathrm{CI}=0.7-2.2)$ with an OR that was slightly higher when limited to premenopausal women $(\mathrm{OR}=2.0 ; 95 \%$ $\mathrm{CI}=0.8-5.4$ ) (Table 2) [48]. Differences in these studies may be due to varying control for confounders, Wild et al. did not adjust for any variables except BMI while Fearnley et al. adjusted for parity and oral contraceptive (OC) use, and Zucchetto et al. adjusted for parity, OC use, age at menarche, and age at menopause. In addition, the study population in Fearnley, et al. was limited to women under age 50 which is likely a primarily premenopausal population.

Endometrial tumors display a variety of histologic features but the majority of cases are adenocarcinomas $(>95 \%)$ and can be classified into two main subtypes, endometrioid (Type I) and non-endometrioid (Type II) $[49,50]$. As approximately $70-80 \%$ of endometrial cancers are Type I tumors the reported associations between PCOS and endometrial cancer are likely driven by this subtype. To our knowledge only one study has examined the association between PCOS and subtype specific endometrial cancer reporting a slightly stronger association between PCOS and endometrial cancer when limited to Type I (OR all cases $=2.2$; $95 \%$ CI $0.9-5.7$ vs. OR Type I cases $=2.4$; 95\% CI $=1.0-6.2)[46]$.

Table 1 Diagnostic criteria for PCOS

\begin{tabular}{llll}
\hline & NIH 1990 Criteria & Rotterdam Criteria & AE-PCOS Society Criteria \\
\hline Hyperandrogenism & Required & 2 out of 3 required & Required \\
Ovulatory dysfunction (oligo- or amenorrhea) & Required & 2 out of 3 required & Either ovulatory dysfunction or PCOS morphology required \\
PCOS morphology & Not required & 2 out of 3 required & Either ovulatory dysfunction or PCOS morphology required \\
\hline
\end{tabular}


Table 2 Studies of PCOS and endometrial cancer risk

\begin{tabular}{|c|c|c|c|c|}
\hline Author & Year & Study design & Endometrial Cancer Cases (n) & Overall result RR $(95 \% \mathrm{Cl})$ \\
\hline Gottschau & 2015 & Registry cohort (Denmark) & 16 & $3.9(2.2-6.3)^{\mathrm{a}}$ \\
\hline Shen & 2015 & Registry cohort (Taiwan) & 7 & $4.7(1.6-14.1)^{\mathrm{a}}$ \\
\hline Barry $^{b}$ & 2014 & Meta-analysis & 1264 & $2.8(1.3-6.0)^{\mathrm{a}}$ \\
\hline Haoula $^{c}$ & 2012 & Meta-analysis & 938 & $2.9(1.5-5.5)^{a}$ \\
\hline Brinton $^{d}$ & 2010 & Cohort (US) & 15 & $2.0(1.1-3.3)^{\mathrm{a}}$ \\
\hline Fearnley ${ }^{e}$ & 2010 & Case control (Australia) & 156 & $2.2(0.9-5.7)$ \\
\hline Chittenden $^{f}$ & 2009 & Meta-analysis & 667 & $2.7(1.0-7.3)^{c}$ \\
\hline Zucchetto & 2009 & Case-control (Italy) & 454 & $1.3(0.7-2.2)$ \\
\hline latrakis $^{e}$ & 2006 & Case-control (Greece) & 81 & $9.0(0.5-176.0)^{a, g}$ \\
\hline Pillay ${ }^{\mathrm{h}}$ & 2006 & Cross-sectional (UK) & 128 & $1.0(0.4-2.7)^{\mathrm{a}, \mathrm{c}}$ \\
\hline Niwa & 2000 & Case-control (Japan) & 136 & $8.9(0.4-184.9)^{\mathrm{a}, \mathrm{g}}$ \\
\hline Wild & 2000 & Cohort (UK) & 11 & $6.1(1.0-36.9)$ \\
\hline Escobedo & 1991 & Case-control (US) & 437 & $5.4(2.4-12.3)^{\mathrm{a}}$ \\
\hline Coulam ${ }^{i}$ & 1983 & Cohort (US) & 5 & $3.1(1.1-7.3)^{\mathrm{a}}$ \\
\hline
\end{tabular}

${ }^{a}$ Effect estimate not adjusted for BMI

b This meta-analysis includes the studies by Fearnley, Zucchetto, latrakis, Niwa, and Escobedo

c This meta-analysis includes the studies by Fearnley, latrakis, Pillay, Niwa, and Escobedo

${ }^{d}$ In this study, androgen excess or menstrual disorders was evaluated rather than PCOS

e This study only included women less than 50 years old

${ }^{f}$ This meta-analysis includes the studies by latrakis, Pillay, Niwa, and Escobedo

${ }^{g}$ Odds ratio was calculated based on numbers provided in the paper

${ }^{\mathrm{h}}$ In this study, polycystic ovary morphology was evaluated rather than PCOS

' In this study, chronic anovulation syndrome was evaluated rather than PCOS

\section{Ovarian cancer}

PCOS has been hypothesized to increase ovarian cancer risk through increased androgen exposure [51]. Evidence linking androgens to ovarian cancer includes the presence of androgen receptors on normal ovarian cells as well as benign and borderline tumors, and a doubling of androgen levels during pregnancy is associated with a $40-50 \%$ increased risk of borderline serous and invasive mucinous tumors [51-53]. However, studies of prediagnostic androgen levels not during pregnancy have been mixed [54-57]. With respect to PCOS specifically, nine studies have examined the association with ovarian

cancer risk to date [39, 43, 44, 58-63]. Many of these studies had limited power, with four studies having 12 or fewer ovarian cancer cases (Table 3) [39, 43, 44, 60, 62]. Overall, studies of PCOS and ovarian cancer have been largely null with some suggestion of an increased risk as demonstrated by a recent meta-analysis of three studies $(\mathrm{OR}=1.4 ; 95 \% \mathrm{CI}=0.9-2.2)$ [34]. Since then a Danish registry study reported a non-significant increase in ovarian cancer risk for women with PCOS compared to the general Danish female population (standardized incidence ratio $[\mathrm{SIR}]=1.8 ; 95 \% \mathrm{CI}=0.8-3.2$ ), but the study was limited by small numbers with only 10 ovarian cases

Table 3 Studies of PCOS and ovarian cancer risk

\begin{tabular}{|c|c|c|c|c|}
\hline Author & Year & Study design & Ovarian Cancer Cases (n) & Overall result RR $(95 \% \mathrm{Cl})$ \\
\hline Harris & 2016 & Case-control (US) & 1513 & $1.0(0.60-1.5)$ \\
\hline Gottschau & 2015 & Registry Cohort (Danish) & 10 & $1.8(0.8-3.2)^{a}$ \\
\hline Shen & 2015 & Registry Cohort (Taiwan) & 11 & $1.0(0.2-4.6)^{a}$ \\
\hline Barry $^{b}$ & 2014 & Meta-analysis & 3363 & $1.4(0.9-2.2)^{a}$ \\
\hline Bodmer & 2011 & Case-control (UK) & 1611 & $1.6(0.7-4.1)^{a}$ \\
\hline Brinton $^{c}$ & 2010 & Cohort (US) & 12 & $1.8(0.9-3.1)^{a}$ \\
\hline Olsen & 2008 & Case-control (Australia) & 1276 & $1.1(0.6-2.0)$ \\
\hline Schildkraut & 1996 & Case-control (US) & 476 & $2.4(1.0-5.9)^{\mathrm{a}}$ \\
\hline Rossing & 1994 & Cohort (US) & 11 & $2.4(0.2-22.5)$ \\
\hline
\end{tabular}

\footnotetext{
${ }^{\mathrm{a}}$ Effect estimate not adjusted for BMI
}

b This meta-analysis includes the studies by Bodmer, Olsen, and Schildkraut

c In this study, androgen excess or menstrual disorders was evaluated rather than PCOS 
[39]. In a recent Taiwanese study with only 11 ovarian cancer cases, no association between PCOS and ovarian cancer was observed (hazard ratio $[\mathrm{HR}]=1.0 ; 95 \% \mathrm{CI}=$ 0.2-4.6) [62]. In the New England Case-control (NECC) study, which includes 1,513 ovarian cancer cases, we observed no association between self-reported PCOS and ovarian cancer risk $(\mathrm{OR}=1.0 ; 95 \% \mathrm{CI}=0.6-1.5)$ [63].

Epithelial ovarian cancer consists of molecularly and etiologically distinct subgroups that can be separated into four main histologic subtypes [64-67]. Thus, an elevation in risk relevant to only certain subtypes of ovarian cancer could be missed if subgroup specific estimates of ovarian cancer are not calculated. Only two studies to date have examined the association by histologic subtype. Olsen, et al. reported an association between PCOS and the borderline serous subtype $(\mathrm{OR}=2.5 ; 95 \% \mathrm{CI}$ 1.0-6.1) and noted this association was strongest among women with a $\mathrm{BMI} \geq 25$ (OR $=3.0$; 95\% CI 1.2-7.5) [59]. Consistent with this result, we observed in the NECC study of ovarian cancer the suggestion of an increased risk of the borderline serous subtype for women with PCOS $(\mathrm{OR}=1.2$; 95\% CI 0.5-2.8) that was also stronger among overweight women [63]. Serous borderline ovarian tumors have been proposed to arise from benign ovarian tumors [68] and have higher androgen receptor levels than serous invasive tumors [52]. Furthermore, in a large European prospective cohort study, prediagnostic androstenedione was shown to increase risk of low-grade tumors $(\mathrm{OR}=1.99 ; 95 \% \mathrm{CI}=0.98-4.06)$ but decrease risk of high grade tumors ( $\mathrm{OR}=0.75 ; 95 \% \mathrm{CI}=0.61-0.93$ ) [57]. Larger studies are needed to further examine whether PCOS is associated with serous borderline tumors and whether this association only pertains to overweight women.

\section{Breast cancer}

Characteristics and consequences of PCOS have been previously associated with both increased and decreased risk of breast cancer. For example, infertility due to an ovulatory disorder has been shown to decrease breast cancer risk [69] while obesity increases breast cancer risk among postmenopausal women and decreases risk among premenopausal women [38]. However, studies to date have not observed an association between PCOS and breast cancer risk (Table 4). A meta-analysis including two case-control studies (from Italy and Iran) and one cohort study (Iowa Women's Health Study) reported no elevation in risk for women with PCOS $(\mathrm{OR}=1.0 ; 95 \% \mathrm{CI}=0.6-1.4)$ [34]. Similarly, a recent Danish registry study showed no association between PCOS and breast cancer risk with 59 breast cases observed and 56 expected resulting in a standardized incidence ratio of $1.1(95 \% \mathrm{CI}=$ 0.8-1.4) [39] and a retrospective cohort study in Taiwan showed no association $(\mathrm{HR}=1.6,95 \% \mathrm{CI}=$ $0.9-2.8)$ [62].

Though women were not specifically classified by PCOS status, we reported in the Nurses' Health Study II, a cohort including more than 100,000 women and followed prospectively, that women who reported infertility due to ovulatory disorders had no increase in breast cancer risk. In fact, women with ovulatory disorders that were treated for infertility had a significantly lower risk compared to women with no reported infertility [69]. Anovulatory cycles skip the luteal phase of the menstrual cycle and it is during the luteal phase that estrogen and progesterone levels are both elevated [70]. In addition, breast cancer cell proliferation is higher during the luteal phase $[71,72]$ thus women with ovulatory

Table 4 Studies of PCOS and breast cancer risk

\begin{tabular}{lllll}
\hline Author & Year & Study design & Breast Cancer Cases (n) & Overall result RR (95\% Cl) \\
\hline Gottschau & 2015 & Registry Cohort (Danish) & 59 & $1.1(0.8-1.4)^{\mathrm{a}}$ \\
Shen & 2015 & Registry Cohort (Taiwan) & 44 & $1.6(0.9-2.8)^{\mathrm{a}}$ \\
Barry $^{\mathrm{b}}$ & 2014 & Meta-analysis & 3618 & $1.0(0.6-1.4)^{\mathrm{a}}$ \\
Ghasemi & 2010 & Case-control (Iran) & 166 & $0.7(0.3-1.5)^{\mathrm{a}}$ \\
Brinton $^{\mathrm{c}}$ & 2010 & Cohort (US) & 89 & $1.3(1.1-1.6)^{\mathrm{a}}$ \\
Terry $^{\mathrm{d}}$ & 2006 & Cohort (US) & 2267 & $0.8(0.6-1.0)$ \\
Wild $_{\text {Anderson }}$ & 2000 & Cohort (UK) & 49 & $1.3(0.6-2.8)$ \\
Talamini & 1997 & Cohort (US) & 883 & $1.2(0.7-2)$ \\
Gammon & 1997 & Case-control (Italy) & 2569 & $0.9(0.4-1.8)$ \\
Coulam $^{\mathrm{e}}$ & 1991 & Case-control (US) & 4730 & $0.47(0.3-0.9)^{\mathrm{a}}$ \\
\hline
\end{tabular}

\footnotetext{
${ }^{a}$ Effect estimate not adjusted for BMI
}

${ }^{\mathrm{b}}$ This meta-analysis includes the studies by Ghasemi, Anderson, and Talamini

${ }^{c}$ In this study, androgen excess or menstrual disorders was evaluated rather than PCOS

d In this study, infertility due to ovulatory disorders was evaluated rather than PCOS

${ }^{\mathrm{e}}$ In this study, chronic anovulation syndrome was evaluated rather than PCOS 
disorders will have a reduced lifetime exposure to luteal phase hormones which may explain the observed reduction in risk.

\section{Other cancers}

The literature examining the association between PCOS and cancers other than endometrial, breast, and ovarian, is scarce. Although not previously described, more kidney, colon, and brain cancers were observed among women with PCOS compared to expected rates in the general Danish population [39]. In addition, Brinton et al. reported a significant standardized incidence ratio for melanoma ( $\mathrm{SIR}=2.0 ; 95 \% \mathrm{CI}=1.1-3.2)$ among infertile women with androgen excess or menstrual cycle disorders compared to the general U.S. population [44]. These findings need to be followed up in large welldesigned studies for validation.

\section{Discussion}

\section{Confounding and mediation}

Since high BMI is a common characteristic of PCOS, [29-31] one cannot exclude the possibility that reported associations may be attributable to a higher BMI in women with PCOS, on average. As noted above, many studies failed to control for BMI and when BMI is taken into account residual confounding may remain since weight is strongly associated with these diseases. In fact, the inverse association between BMI and breast cancer among premenopausal women but positive association among postmenopausal women may explain, in part, the lack of an association with breast cancer [38]. Conversely, there is evidence that PCOS influences body size through dietary intake and cravings, $[73,74]$ as well as through its influence on metabolic factors that may impact weight gain [75-81]. Thus BMI may be both a mediator and confounder of the PCOS and cancer associations making it difficult to characterize a BMIindependent PCOS association.

Beyond BMI, the adjustment for cancer risk factors varied widely between studies and may also explain differences between studies as some characteristics of PCOS, such as infertility, are risk factors for these cancers. Reproductive risk factors such as parity and age at first birth may have different distributions in those with and without PCOS due to the increased risk of infertility in women with PCOS. In addition, women with PCOS are at increased risk of type II diabetes [20, 21], insulin resistance, and metabolic syndrome [15-19]. These conditions have been associated with cancer risk, $[82,83]$ and thus could serve either as potential confounders or intermediates, of the PCOS-cancer association. A few studies have adjusted for these potential intermediate variables (i.e. hypertension and diabetes), which may have resulted in an attenuation of the true association $[46,62]$.

\section{Possible biologic mechanisms}

PCOS is characterized by prolonged anovulation with consequent exposure to estrogen unopposed by progesterone [33, 84], which may explain why women with PCOS have an elevated risk of endometrial cancer, an estrogen-sensitive disease. The association between estrogen and breast or ovarian cancer are more complex and depend on subtypes of disease and menopausal status, $[65,66,85,86]$ which may explain the lack of overall increased risk for these cancers. Larger studies, or pooled analyses, are needed which would allow investigation of these associations by specific subtypes and menopausal status.

Alternatively, elevated androgens may play a role. Hyperandrogenism is one major component of all three clinical diagnostic criteria for PCOS. In 1998, Risch proposed that ovarian cancer might be associated with factors related to androgen stimulation of ovarian cells,[51] and animal studies have demonstrated that testosterone stimulates the growth of epithelial cells in the ovary [87]. The suggestion of an increased risk of the borderline serous subtype of ovarian cancer among women with PCOS supports the hypothesis that androgens could be a factor in ovarian cancer development as androgen receptors have been shown to be higher in serous borderline tumors compared to serous invasive [52]. Circulating androgens may also play a role in breast carcinogenesis [88]. In a pooled analysis of prospective studies, risk of breast cancer has been shown increase with increasing testosterone levels in postmenopausal women [89]. A similar increased risk has been reported by cohort studies among premenopausal women $[90,91]$.

\section{PCOS medications that may influence cancer risk Oral contraceptives}

For women who are not attempting to become pregnant, combined oral contraceptives are often one of the first-line treatments for menstrual irregularities in women with PCOS [92]. Combined oral contraceptives are associated with decreased risk of ovarian [93] and endometrial cancers [94]. The protective effect of oral contraceptives on ovarian cancer risk is likely explained by a decreased lifetime number of potentially damaging ovulations,[95] while the protective effect in endometrial cancer may be the result of reducing exposure to unopposed estrogen which limits the cell proliferation that is stimulated by estrogens [84]. In contrast, oral contraceptives may result in a very small short-term increase in breast cancer risk, while 10 years after cessation of use the risk among women who had used oral contraceptives was similar to those who had not used oral contraceptives [96]. 


\section{Metformin}

Among women with PCOS, metformin is prescribed to treat or reduce the risk of type II diabetes, improve insulin resistance, and in some cases to help regulate the menstrual cycle/induce ovulation. Evidence has suggested that metformin use may be protective against various forms of cancer. This is supported by laboratory studies that demonstrate metformin's anti-cancer activities [97]. However, fewer studies have examined the impact of metformin on incidence of endometrial, breast, and ovarian cancer.

Breast cancer has been the most studied of the three cancers with respect to the influence of metformin. A 2014 meta-analysis including 13 studies reported a summary risk estimate (SRR) of 0.9 (95\% CI =0.8-1.0) for the association between metformin use and breast cancer incidence [98]. When limited to the studies which adjusted for BMI $(n=7)$, an established risk factor for postmenopausal breast cancer, the SRR was 0.8 (95\% $\mathrm{CI}=0.7-1.0)$, and when limited to prospective studies $(n=7)$, the SRR was $0.9(95 \% \mathrm{CI}=0.9-1.0)$. However, a more recent analyses among women in general practice databases from Germany and the United Kingdom reported no association between metformin users and breast cancer incidence when compared users of sulfonylurea and insulin $(\mathrm{HR}=1.0 ; 95 \% \mathrm{CI}=0.8-1.3$ and $\mathrm{HR}=1.1 ; 95 \% \mathrm{CI}=0.7-1.7$, respectively) [99].

The epidemiologic data examining the relation between metformin and endometrial cancer have generally suggested no association or a protective association between metformin and endometrial cancer. Among women in the UK-based General Practice Research Database (GPRD) no significant association was observed between metformin and endometrial cancer with an OR of $0.9(95 \% \mathrm{CI}=0.6-1.2)$ [100] Similarly, in a retrospective cohort analysis of US healthcare claims data no association was observed between metformin use and endometrial cancer $(\mathrm{HR}=1.1 ; 95 \% \mathrm{CI}=0.9$ 1.4) [101]. Most recently, Tseng reported an inverse association between metformin and endometrial cancer among women with type II diabetes in the National Health Insurance database in Taiwan $(\mathrm{HR}=$ 0.7; 95\% CI $=0.6-0.7$ ) [102].

The association between metformin use and ovarian cancer has been less studied than breast or endometrial cancer. However, metformin use has been demonstrated to influence ovarian cancer cell growth in vitro and in vivo [103, 104] and has been associated with survival in patients with ovarian cancer $[105,106]$. To our knowledge, only one observational study has reported the association between metformin and risk of ovarian cancer observing the suggestion of a decreased risk of ovarian cancer with increasing metformin use $(\mathrm{OR}=0.6 ; 95 \% \mathrm{CI}=$ 0.3-1.3) among women in the UK-based GPRD [58].

\section{Ovulation-induction therapies}

Previous studies on the associations between fertility drugs and risk of hormone related cancers have produced mixed results. The inconsistencies are likely due to the combining of different drug types, self-reported drugs use, limited power and information about dosages, short follow-up, and reproductive confounders that are highly correlated with drug use [107]. Clomiphene (clomid), a common treatment for PCOS-associated infertility, is a selective estrogen receptor modulator that stimulates the ovaries to ovulate but can increase or decrease estrogen receptor activation in other tissues. In breast cancer cell lines, clomiphene has a pro-apoptotic effect,[108] which may explain why women who received clomiphene for PCOS-related infertility have a reduced breast cancer risk in some studies [69, 109]. A more recent study in a cohort of over 12,000 infertile women reported that clomiphene was not associated with breast cancer risk, although a non-significant increased risk was observed for those with over 12 cycles [110].

Clomiphene's action as an ovulation inducer provides strong biological plausibility for its influence on ovarian cancer risk as ovulatory damage likely plays a prominent role in ovarian cancer risk [95]. Most recent studies have indicated no significant increased risk of ovarian cancer among clomiphene users [107]. In a large cohort of women evaluated for infertility with extended follow-up Trabert, et al. reported no overall association between clomiphene use and ovarian cancer risk $(\mathrm{HR}=1.3 ; 95 \%$ $\mathrm{CI}=0.9-2.1)$, however they did note an increased risk among women who remained infertile $(\mathrm{HR}=3.6 ; 95 \%$ 1.4-9.7) [111] and this increased risk in nulligravid women has been observed in other studies [107]. Whether this indicates confounding by infertility severity or a true effect deserves further study.

Endometrial cancer has been the least studied of the hormone related cancers in relation to clomiphene use. An association has been hypothesized since clomiphene has chemical properties similar to tamoxifen, a drug that has been associated with endometrial cancer risk [112]. However, most previous studies of clomiphene and endometrial cancer have been limited by power [107]. In one of the largest studies to date Brinton et al. reported a slight non-significant increase in risk of endometrial cancer among clomiphene users $(\mathrm{HR}=1.4 ; 95 \% \mathrm{CI}=$ 1.0-2.0) [113].

Fewer studies have examined the associations between clomiphene and cancers other then endometrial, ovarian, or breast cancer. A recent analysis in a cohort of over 12,000 infertile women reported that clomiphene was statistically significant increased risk of melanoma ( $\mathrm{HR}=2.0 ; 95 \% \mathrm{CI}=1.2-3.2)$, a non-significant increased risk of thyroid cancer $(1.6 ; 95 \% \mathrm{CI}=0.9-2.8)$, and no increased risks for colorectal or lung cancer [114]. 
Letrozole, an aromatase inhibitor, has more recently been considered as an additional treatment option for anovulatory infertility. While longitudinal data does not yet exist to adequately examine the association between letrozole use for ovulatory infertility and hormone related cancer risk, letrozole is currently used as an adjuvant treatment for hormone receptor positive postmenopausal breast cancer [115] thus it could be hypothesized that it would likely decrease hormonal related cancer risk.

\section{Conclusions}

The associations between PCOS and endometrial, ovarian, and breast cancer are complex, requiring consideration of PCOS diagnostic criteria, etiologic heterogeneity of cancer subtypes, confounding and mediating factors, menopausal status, co-morbid conditions, as well as treatment options that may also influence cancer risk. In addition, the rarity of ovarian and endometrial cancers make these cancers even more difficult to study. Larger well-designed studies, or pooled analyses, may help clarify these complex associations.

\section{Abbreviations \\ BMI: Body mass index; Cl: Confidence interval; ESHRE/ASRM: European society for human reproduction and embryology/American society for reproductive medicine; GPRD: General practice research database; HR: Hazard ratio; NECC: New England case-control; NIH/NICHD: National institutes of health/national institute of child health and human disease; OR: Odds ratio; PCO: Polycystic ovaries; PCOS: Polycystic ovary syndrome; SIR: Standardized incidence ratio; SRR: Summary risk estimate}

\section{Acknowledgements}

Not applicable.

\section{Funding}

HRH is supported by the National Cancer Institute, National Institutes of Health (K22 CA193860). KLT is supported by the Department of Defense (W81XWH-10-1-0280). The funding sources had no role in the design of the study, collection of data, data analysis, or writing of the manuscript.

\section{Availability of data and materials}

Data sharing not applicable to this article as no datasets were generated or analysed during the current study.

\section{Authors' contributions}

HRH and KLT conceived and designed the study and drafted and finalized the manuscript. Both authors read and approved the final manuscript.

\section{Competing interests}

The authors declare they have no competing interests.

\section{Consent for publication}

Not applicable.

\section{Ethical approval and consent to participate}

Not applicable.

\section{Author details}

'Program in Epidemiology, Division of Public Health Sciences, Fred Hutchinson Cancer Research Center, M4-859 Seattle, WA, USA. ${ }^{2}$ Department of Obstetrics and Gynecology, Brigham and Women's Hospital and Harvard Medical School, Boston, MA, USA. ${ }^{3}$ Department of Epidemiology, Harvard T.H. Chan School of Public Health, Boston, MA, USA.
Received: 20 August 2016 Accepted: 25 November 2016

Published online: 05 December 2016

\section{References}

1. Azziz R, Woods KS, Reyna R, Key TJ, Knochenhauer ES, Yildiz BO. The Prevalence and Features of the Polycystic Ovary Syndrome in an Unselected Population. J Clin Endocrinol Metab. 2004;89:2745-9.

2. Dokras A, Witchel SF. Are Young Adult Women with Polycystic Ovary Syndrome Slipping through the Healthcare Cracks? I Clin Endocrinol Metab. 2014;99(5):1583-5. doi:10.1210/jc.2013-4190.

3. Sirmans S, Pate K. Epidemiology, diagnosis, and management of polycystic ovary syndrome. Clin Epidemiol. 2013;6:1-13.

4. March WA, Moore VM, Willson KJ, Phillips DIW, Norman RJ, Davies MJ. The prevalence of polycystic ovary syndrome in a community sample assessed under contrasting diagnostic criteria. Hum Reprod. 2010;25:544-51.

5. Mehrabian F, Khani B, Kelishadi R, Ghanbari E. The prevalence of polycystic ovary syndrome in Iranian women based on different diagnostic criteria. Endokrynol Pol. 2011;62:238-42.

6. Tehrani F, Simbar M, Tohidi M, Hosseinpanah F, Azizi F. The prevalence of polycystic ovary syndrome in a community sample of Iranian population: Iranian PCOS prevalence study. Reprod Biol Endocrinol. 2011;9:39.

7. Yildiz BO, Bozdag G, Yapici Z, Esinler I, Yarali H. Prevalence, phenotype and cardiometabolic risk of polycystic ovary syndrome under different diagnostic criteria. Hum Reprod. 2012;27:3067-73.

8. Johnson TRB, Kaplan LK, Ouyang P, Rizza RA. National Institutes of Health, Evidence-based Methodology Workshop on Polycystic Ovary Syndrome: Executive Summary. Bethesda: NIH; 2012. (Health Nlo ed.).

9. Ovalle F, Azziz R. Insulin resistance, polycystic ovary syndrome, and type 2 diabetes mellitus. Fertil Steril. 2002;77:1095-105.

10. Wild RA. Long-term health consequences of PCOS. Hum Reprod Update. 2002;8:231-41.

11. Stein I, Leventhal M. Amenorrhea associated with bilateral polycystic ovaries Am J Obstet Gynecol. 1935;29:181-5.

12. Zawadski J, Dunaif A. Diagnostic criteria for polycystic ovary syndrome. In: Givens JHF MG, editor. The Polycystic Ovary Syndrome. Cambridge: Blackwell Scientific; 1992. p. 377-84.

13. Group REA-SPCW. Revised 2003 consensus on diagnostic criteria and long-term health risks related to polycystic ovary syndrome. Fertil Steril. 2004:81:19-25.

14. Azziz R, Carmina E, Dewailly D, Diamanti-Kandarakis E, Escobar-Morreale HF, Futterweit W, Janssen OE, Legro RS, Norman RJ, Taylor AE, Witchel SF. Criteria for Defining Polycystic Ovary Syndrome as a Predominantly Hyperandrogenic Syndrome: An Androgen Excess Society Guideline. J Clin Endocrinol Metab. 2006;91:4237-45.

15. Carmina E, Lobo R. Use of fasting blood to assess the prevalence of insulin resistance in women with polycystic ovary syndrome. Fertil Steril. 2004;82: 661-5.

16. Dunaif A. Insulin Resistance and the Polycystic Ovary Syndrome: Mechanism and Implications for Pathogenesis. Endocr Rev. 1997;18:774-800.

17. Schachter M, Raziel A, Friedler S, Strassburger D, Bern O, Ron-El R. Insulin resistance in patients with polycystic ovary syndrome is associated with elevated plasma homocysteine. Hum Reprod. 2003;18:721-7.

18. Dunaif A, Segal KR, Futterweit W, Dobrjansky A. Profound Peripheral Insulin Resistance, Independent of Obesity, in Polycystic Ovary Syndrome. Diabetes. 1989;38:1165-74.

19. Moran $\amalg$, Misso ML, Wild RA, Norman RJ. Impaired glucose tolerance, type 2 diabetes and metabolic syndrome in polycystic ovary syndrome: a systematic review and meta-analysis. Hum Reprod Update. 2010;16:347-63.

20. Ehrmann DA, Barnes RB, Rosenfield RL, Cavaghan MK, Imperial J. Prevalence of impaired glucose tolerance and diabetes in women with polycystic ovary syndrome. Diabetes Care. 1999;22:141-6.

21. Legro RS, Kunselman AR, Dodson WC, Dunaif A. Prevalence and Predictors of Risk for Type 2 Diabetes Mellitus and Impaired Glucose Tolerance in Polycystic Ovary Syndrome: A Prospective, Controlled Study in 254 Affected Women. J Clin Endocrinol Metab. 1999;84:165-9.

22. Dejager S, Pichard C, Giral P, Bruckert E, Federspield M, Beucier I, Turpin G. Smaller LDL particle size in women with polycystic ovary syndrome compared to controls. Clin Endocrinol (Oxf). 2001;54:455-62.

23. Legro R, Blanche P, Krauss R, Lobo R. Alterations in low-density lipoprotein and high-density lipoprotein subclasses among Hispanic women with 
polycystic ovary syndrome: influence of insulin and genetic factors. Fertil Steril. 1999;72:990-5.

24. Pirwany I, Fleming R, Greer I, Packard C, Sattar N. Lipids and lipoprotein subfractions in women with PCOS: relationship to metabolic and endocrine parameters. Clin Endocrinol (Oxf). 2001;54:447-53.

25. Wild R, Rizzo M, Clifton S, Carmina E. Lipid levels in polycystic ovary syndrome: systematic review and meta-analysis. Fertil Steril. 2011;95:1073-9.

26. Elting MW, Korsen TJM, Bezemer PD, Schoemaker J. Prevalence of diabetes mellitus, hypertension and cardiac complaints in a follow-up study of a Dutch PCOS population. Hum Reprod. 2001;16:556-60.

27. Lo JC, Feigenbaum SL, Yang J, Pressman AR, Selby JV, Go AS. Epidemiology and Adverse Cardiovascular Risk Profile of Diagnosed Polycystic Ovary Syndrome. J Clin Endocrinol Metab. 2006;91:1357-63.

28. Vrbíková J, Cífková R, Jirkovská A, Lánská V, Platilová H, Zamrazil V, Stárka L. Cardiovascular risk factors in young Czech females with polycystic ovary syndrome. Hum Reprod. 2003;18:980-4

29. Lim SS, Davies MJ, Norman RJ, Moran LJ. Overweight, obesity and central obesity in women with polycystic ovary syndrome: a systematic review and meta-analysis. Hum Reprod Update. 2012;18:618-37.

30. Alvarez-Blasco F, Botella-Carretero J, San Millan J, Escobar-Morreale H. Prevalence and characteristics of the polycystic ovary syndrome in overweight and obese women. Arch Intern Med. 2006;166:2081-6.

31. Yildiz BO, Knochenhauer ES, Azziz R. Impact of Obesity on the Risk for Polycystic Ovary Syndrome. J Clin Endocrinol Metab. 2008;93:162-8.

32. Legro RS, Arslanian SA, Ehrmann DA, Hoeger KM, Murad MH, Pasquali R, Welt CK. Diagnosis and Treatment of Polycystic Ovary Syndrome: An Endocrine Society Clinical Practice Guideline. J Clin Endocrinol Metab. 2013;98:4565-92.

33. Hardiman P, Pillay O, Atiomo W. Polycystic ovary syndrome and endometrial carcinoma. Lancet. 2003:361:1810-2.

34. Barry JA, Azizia MM, Hardiman PJ. Risk of endometrial, ovarian and breast cancer in women with polycystic ovary syndrome: a systematic review and meta-analysis. Hum Reprod Update. 2014;20:748-58.

35. Chittenden B, Fullerton G, Maheshwari A, Bhattacharya S. Polycystic ovary syndrome and the risk of gynaecological cancer: a systematic review. Reprod Biomed Online. 2009;19:398-405.

36. Haoula Z, Salman M, Atiomo W. Evaluating the association between endometrial cancer and polycystic ovary syndrome. Hum Reprod. 2012;27: 1327-31.

37. Crosbie EJ, Zwahlen M, Kitchener HC, Egger M, Renehan AG. Body Mass Index, Hormone Replacement Therapy, and Endometrial Cancer Risk: A Meta-Analysis. Cancer Epidemiol Biomarkers Prev. 2010;19:3119-30.

38. AICR. Food, Nutrition, Physical Activity, and the Prevention of Cancer: a Global Perspective. Washington: AICR; 2007.

39. Gottschau M, Kjaer S, Jensen A, Munk C, Mellenmkjaer L. Risk of cancer among women with polycystic ovary syndrome: a Danish cohort study. Gynecol Oncol. 2015;136:99-103.

40. Escobedo L, Lee N, Peterson H, Wingo P. Infertility-associated endometrial cancer risk may be limited to specific subgroups of infertile women. Obstet Gynecol. 1991;77:124-8.

41. Niwa K, Imai A, Hashimoto M, Yokoyama Y, Mori H, Matsuda Y, Tamaya T. A case-control study of uterine endometrial cancer of pre- and postmenopausal women. Oncol Rep. 2000;7:89-03.

42. latrakis G, Zervoudis S, Saviolakis A, Troulous M, Antonious E, Sarantaki A Lykeridou K, Kourounis $\mathrm{G}$. Women younger than 50 years with endometrial cancer. Eur J Gynaecol Oncol. 2006;27:399-400.

43. Coulam C, Annegers J, Kranz J. Chronic anovulation syndrome and associated neoplasia. Obstet Gynecol. 1983;61:403-7.

44. Brinton L, Moghissi K, Westhoff C, Lamb E, Scoccia B. Cancer risk among infertile women with androgen excess or menstrual disorders (including polycystic ovary syndrome). Fertil Steril. 2010;94:1787-92.

45. Pillay OC, Te Fong LFW, Crow JC, Benjamin E, Mould T, Atiomo W, Menon PA, Leonard AJ, Hardiman P. The association between polycystic ovaries and endometrial cancer. Hum Reprod. 2006:21:924-9.

46. Fearnley EJ, Marquart L, Spurdle AB, Weinstein P, Webb PM. Polycystic ovary syndrome increases the risk of endometrial cancer in women aged less than 50 years: an Australian case-control study. Cancer Causes Control. 2010;21:2303-8

47. Wild S, Pierpoint T, Jacobs H, McKeigue P. Long-term consequences of polycystic ovary syndrome: results of a 31-year follow-up study. Hum Fertil (Camb). 2000;3:101-5.
48. Zucchetto A, Serraino D, Polesel J, Negri E, De Paoli A, Dal Maso L, Montella M, La Vecchia C, Franceschi S, Talamini R. Hormone-related factors and gynecological conditions in relation to endometrial cancer risk. Eur J Cancer Prev. 2009:18:316-21.

49. Bokhman J. Two pathogenetic types of endometrial carcinoma. Gynecol Oncol. 1983:15:10-7.

50. Deligdisch L, Holinka C. Endometrial carcinoma: two diseases? Cancer Detect Prev. 1987;10:237-46.

51. Risch HA. Hormonal Etiology of Epithelial Ovarian Cancer, With a Hypothesis Concerning the Role of Androgens and Progesterone. J Natl Cancer Inst. 1998;90:1774-86.

52. Butler M, Ricciardelli C, Tilley W, Hickey T. Androgen Receptor Protein Levels Are Significantly Reduced in Serous Ovarian Carcinomas Compared with Benign or Borderline Disease but Are Not altered by Cancer Stage or Metastatic Progression. Horm Cancer. 2013:4:154-64.

53. Schock H, Surcel H-M, Zeleniuch-Jacquotte A, Grankvist K, Lakso H- $\AA$, Fortner RT, Kaaks R, Pukkala E, Lehtinen M, Toniolo P, Lundin E. Early pregnancy sex steroids and maternal risk of epithelial ovarian cancer. Endocr Relat Cancer. 2014;21:831-44.

54. Helzlsouer K, Alberg A, Gordon G, Longcope C, Bush T, Hoffman S, Comstock G. Serum gonadotropins and steroid hormones and the development of ovarian cancer. JAMA. 1995;274:1926-30.

55. Rinaldi S, Dossus L, Lukanova A, Peeters PHM, Allen NE, Key T, Bingham S, Khaw K-T, Trichopoulos D, Trichopoulou A, et al. Endogenous Androgens and Risk of Epithelial Ovarian Cancer: Results from the European Prospective Investigation into Cancer and Nutrition (EPIC). Cancer Epidemiol Biomarkers Prev. 2007;16:23-9.

56. Tworoger SS, Lee I-M, Buring JE, Hankinson SE. Plasma Androgen Concentrations and Risk of Incident Ovarian Cancer. Am J Epidemiol. 2008; 167:211-8.

57. Ose J, Fortner RT, Rinaldi S, Schock H, Overvad K, Tjonneland A, Hansen L, Dossus L, Fournier A, Baglietto L, et al. Endogenous androgens and risk of epithelial invasive ovarian cancer by tumor characteristics in the European Prospective Investigation into Cancer and Nutrition. Int J Cancer. 2015;136: 399-410.

58. Bodmer M, Becker C, Meier C, Jick SS, Meier CR. Use of metformin and the risk of ovarian cancer: A case-control analysis. Gynecol Oncol. 2011; 123:200-4.

59. Olsen CM, Green AC, Nagle CM, Jordan SJ, Whiteman DC, Bain CJ, Webb PM, Group obotACS, Group tAOCS. Epithelial ovarian cancer: testing the 'androgens hypothesis'. Endocr Relat Cancer. 2008;15:1061-8.

60. Rossing MA, Daling JR, Weiss NS, Moore DE, Self SG. Ovarian Tumors in a Cohort of Infertile Women. N Engl J Med. 1994;331:771-6.

61. Schildkraut J, Schwingl P, Bastos E, Evanoff A, Hughes C. Epithelial ovarian cancer risk among women with polycystic ovary syndrome. Obstet Gynecol. 1996:88:554-9.

62. Shen C-C, Yang AC, Hung J-H, Hu L-Y, Tsai S-J. A Nationwide Population-Based Retrospective Cohort Study of the Risk of Uterine, Ovarian and Breast Cancer in Women With Polycystic Ovary Syndrome. Oncologist. 2015;20:45-9.

63. Harris H, Titus L, Cramer D, Terry K. Long and irregular menstrual cycles, polycystic ovary syndrome, and ovarian cancer risk in a population-based case-control study. Int J Cancer. 2016.

64. Dubeau $L$. The cell of origina of ovarian epithelial tumors and the ovarian surface epithelium dogma: does the emperor have no clothes? Gynecol Oncol. 1999;72:437-42.

65. Kurman R, Shih I. The origin and pathogenesis of epithelial ovarian cancer: a proposed unifying theory. Am J Surg Pathol. 2010;34:433-43.

66. Kurman R, Shih I. Molecular pathogenesis and extraovarian origin of epithelial ovarian cancer-shifting the paradigm. Hum Pathol. 2011;42: 918-31.

67. Vaughan S, Coward J, Berchuck A, Berek J, Brenton J, Coukos G, Crum C Drapkin R, Etemadmoghadam D, Friedlander $M$, et al. Rethinking ovarian cancer: recommendations for improving outcomes. Nat Rev Cancer. 2011; 11:719-25.

68. Jordan S, Green A, Webb P. Benign Epithelial Ovarian Tumours-cancer Precursors or Markers for Ovarian Cancer Risk? Cancer Causes Control. 2006; 17:623-32.

69. Terry K, Willett W, Rich-Edwards J, Michels K. A prospective study of infertility due to ovulatory disorders, ovulation induction, and incidence of breast cancer. Arch Intern Med. 2006;166:2484-9. 
70. Vander A, Sherman J, Luciano D. Human Physiology: The Mechanisms of Body Function. 8th ed. New York: McGraw-Hill; 2001.

71. Masters JRW, Drife JO, Scarisbrick JJ. Cyclic Variation of DNA Synthesis in Human Breast Epithelium. J Natl Cancer Inst. 1977;58:1263-5.

72. Meyer JS. Cell proliferation in normal human breast ducts, fibroadenomas, and other ductal hyperplasias measured by nuclear labeling with tritiated thymidine. Hum Pathol. 1977;8:67-81.

73. Douglas CC, Norris LE, Oster RA, Darnell BE, Azziz R, Gower BA. Difference in dietary intake between women with polycystic ovary syndrome and healthy controls. Fertil Steril. 2006;86:411-7.

74. Lim SS, Norman RJ, Clifton PM, Noakes M. Hyperandrogenemia, psychological distress, and food cravings in young women. Physiol Behav. 2009;98:276-80.

75. Aas A, Ohrvik J, Malmberg K, Ryden L, Birkeland K. Insulin-induced weight gain and cardiovascular events in patients with type 2 diabetes. A report from the DIGAMI 2 study. Diabetes Obes Metab. 2009;11:323-9.

76. Baranowska B, Radzikowska M, Wasilewska-Dziubińska E, Kapliński A, Roguski K, Płonowski A. Neuropeptide $Y$, leptin, galanin and insulin in women with polycystic ovary syndrome. Gynecol Endocrinol. 1999;13:344-51.

77. Georgopoulos NA, Saltamavros AD, Vervita V, Karkoulias K, Adonakis G, Decavalas G, Kourounis G, Markou KB, Kyriazopoulou V. Basal metabolic rate is decreased in women with polycystic ovary syndrome and biochemical hyperandrogenemia and is associated with insulin resistance. Fertil Steril. 2009:92:250-5.

78. Hirschberg A, Naessén S, Stridsberg M, Byström B, Holte J. Impaired cholecystokinin secretion and disturbed appetite regulation in women with polycystic ovary syndrome. Gynecol Endocrinol. 2004;19:79-87.

79. Moran LJ, Noakes M, Clifton PM, Wittert GA, Le Roux CW, Ghatei MA, Bloom SR, Norman RJ. Postprandial ghrelin, cholecystokinin, peptide YY, and appetite before and after weight loss in overweight women with and without polycystic ovary syndrome. Am J Clin Nutr. 2007:86:1603-10.

80. Moran LJ, Noakes M, Clifton PM, Wittert GA, Tomlinson L, Galletly C, Luscombe ND, Norman RJ. Ghrelin and Measures of Satiety Are Altered in Polycystic Ovary Syndrome But Not Differentially Affected by Diet Composition. J Clin Endocrinol Metab. 2004;89:3337-44.

81. Robinson S, Chap S, Spacey S, Anyaoku V, Johnston D, Franks S. Postprandial thermogenesis is reduced in polycystic ovary syndrome and is associated with increased insulin resistance. Clin Endocrinol (Oxf). 1992;36: 537-43.

82. Shikata K, Ninomiya T, Kiyohara Y. Diabetes mellitus and cancer risk: Review of the epidemiological evidence. Cancer Sci. 2013;104:9-14.

83. Giovannucci E. Metabolic syndrome, hyperinsulinemia, and colon cancer: a review. Am J Clin Nutr. 2007:86:5836-42.

84. Key T, Pike M. The dose-effect relationship between 'unopposed' oestrogens and endometrial mitotic rate: its central role in explaining and predicting endometrial cancer risk. Br J Cancer. 1988:57:205-12.

85. Brown S, Hankinson S. Endogenous estrogens and the risk of breast, endometrial, and ovarian cancers. Steroids. 2015:99:8-10.

86. Yang XR, Chang-Claude J, Goode EL, Couch FJ, Nevanlinna H, Milne RL, Gaudet M, Schmidt MK, Broeks A, Cox A, et al. Associations of Breast Cancer Risk Factors With Tumor Subtypes: A Pooled Analysis From the Breast Cancer Association Consortium Studies. J Natl Cancer Inst. 2011;103:250-63.

87. Silva E, Tornos C, Fritsche HJ, El-Naggar A, Gray K, Ordonez N, Luna M, Gershenson D. The induction of benign epithelial neoplasms of the ovaries of guinea pigs by testosterone stimulation: a potential animal model. Mod Pathol. 1997;10:879-83.

88. Eliassen A, Hankinson S. Endogenous hormone levels and risk of breast, endometrial and ovarian cancers: prospective studies. Adv Exp Med Biol. 2008;630:148-65.

89. Hormones TE, Group BCC. Endogenous Sex Hormones and Breast Cancer in Postmenopausal Women: Reanalysis of Nine Prospective Studies. J Natl Cancer Inst. 2002;94:606-16.

90. Eliassen AH, Missmer SA, Tworoger SS, Spiegelman D, Barbieri RL, Dowsett M, Hankinson SE. Endogenous Steroid Hormone Concentrations and Risk of Breast Cancer Among Premenopausal Women. J Natl Cancer Inst. 2006;98:1406-15.

91. Kaaks R, Berrino F, Key T, Rinaldi S, Dossus L, Biessy C, Secreto G, Amiano P, Bingham S, Boeing H, et al. Serum Sex Steroids in Premenopausal Women and Breast Cancer Risk Within the European Prospective Investigation into Cancer and Nutrition (EPIC). J Natl Cancer Inst. 2005:97:755-65.

92. Rocca M, Venturella R, Mocciaro R, Di Cello A, Sacchinelli A, Russo V, Trapasso S, Zullo F, Morelli M. Polycystic ovary syndrome: chemical pharmacotherapy. Expert Opin Pharmocother. 2015;16:1369-93.
93. La Vecchia C. Oral contraceptives and ovarian cancer: an update, 19982004. Eur J Cancer Prev. 2006;15:117-24.

94. Cancer CGoESoE. Endometrial cancer and oral contraceptives: an individual participant meta-analysis of 27276 women wiht endometrial cancer from 36 epidemiological studies. Lancet Oncol. 2015;16:1061-70.

95. Fathalla M. Incessant ovulation-a factor in ovarian neoplasia? Lancet. 1971;2:163.

96. Humans IWGotEoCRt. Combined estrogen-protestogen contraceptives and combined estrogen-progesterone menopausal therapy. IARC Monogr Eval Carcinog Risks Hum. 2007;91:1-528.

97. Pollak MN. Investigating Metformin for Cancer Prevention and Treatment: The End of the Beginning. Cancer Discov. 2012;2:778-90.

98. Gandini S, Puntoni M, Heckman-Stoddard BM, Dunn BK, Ford L, DeCensi A, Szabo E. Metformin and Cancer Risk and Mortality: A Systematic Review and Meta-analysis Taking into Account Biases and Confounders. Cancer Prev Res. 2014:7:867-85.

99. Kowall B, Stang A, Rathmann W, Kostev K. No reduced risk of overall, colorectal, lung, breast, and prostate cancer with metformin therapy in diabetic patients: database analyses from Germany and the UK Pharmacoepidemiol Drug Saf. 2015;24:865-74.

100. Becker C, Jick S, Meier C, Bodmer M. Metformin and the risk of endometrial cancer: a case-control analysis. Gynecol Oncol. 2013;129:565-9.

101. Ko E, Stürmer T, Hong J, Castillo W, Bae-Jump V, Funk M. Metformin and the risk of endometrial cancer: a population-based cohort study. Gynecol Oncol. 2015;136:341-7.

102. Tseng C. Metformin and endometrial cancer risk in Chinese women with type 2 diabetes mellitus in Taiwan. Gynecol Oncol. 2015;138:147-53.

103. Rattan R, Giri S, Hartmann LC, Shridhar V. Metformin attenuates ovarian cancer cell growth in an AMP-kinase dispensable manner. J Cell Mol Med. 2011;15:166-78.

104. Rattan R, Graham R, Maquire J, Giri S, Shridhar V. Metformin suppresses ovarian cancer growth and metastasis with enhancement of cisplatin cytotoxicity in vivo. Neoplasia. 2011;13:483-91.

105. Kumar S, Meuter A, Thapa P, Langstraat C, Giri S, Chien J, Rattan R, Cliby W, Shridhar $\mathrm{V}$. Metformin intake is associated with better survival in ovarian cancer. Cancer. 2013;119:555-62.

106. Romero I, McCormick A, McEwen I, Park S, Karrison T, Yamada S, Pannain S, Lengyel E. Relationship of type II diabetes and metformin use to ovarian cancer progression, survival, and chemosensitivity. Obstet Gynecol. 2012; 119:61-7.

107. Brinton L, Sahasrabuddhe V, Scoccia B. Fertility drugs and the risk of breast and gynecologic cancers. Semin Reprod Med. 2012;30:131-45.

108. Elloumi-Mseddi J, Jemel-Oualha I, Beji A, Hakim B, Aifa S. Effect of estradio and clomiphene citrate on Erk activation in breast cancer cells. J Recept Signal Transduct Res. 2015;35:202-6.

109. Rossing M, Daling J, Weiss N, Moore D, Self S. Risk of breast cancer in a cohort of infertile women. Gynecol Oncol. 1996;60:3-7.

110. Brinton LA, Scoccia B, Moghissi KS, Westhoff CL, Niwa S, Ruggieri D, Trabert B, Lamb EJ. Long-term Relationship of Ovulation-Stimulating Drugs to Breast Cancer Risk. Cancer Epidemiol Biomarkers Prev. 2014;23:584-93.

111. Trabert B, Lamb E, Scoccia B, Moghissi K, Westhoff C, Niwa S, Brinton L. Ovulation-inducing drugs and ovarian cancer risk: results from an extended follow-up of a large United States infertility cohort. Fertil Steril. 2013;100: 1660-6.

112. Varras M, Polyzos D, Akrivis C. Effects of tamoxifen on the human female genitcal tract: review of the literature. Eur J Gynaecol Oncol. 2003;24:258-68.

113. Brinton LA, Westhoff CL, Scoccia B, Lamb EJ, Trabert B, Niwa S, Moghissi KS. Fertility drugs and endometrial cancer risk: results from an extended followup of a large infertility cohort. Hum Reprod. 2013;28:2813-21

114. Brinton L, Moghissi K, Scoccia B, Lamb E, Trabert B, Niwa S, Ruggieri D, Westhoff $C$. Effects of fertility drugs on cancers other than breast and gynecologic malignancies. Fertil Steril. 2015:104:980-8.

115. Burstein HJ, Prestrud AA, Seidenfeld J, Anderson H, Buchholz TA, Davidson NE, Gelmon KE, Giordano SH, Hudis CA, Malin J, et al. American Society of Clinical Oncology Clinical Practice Guideline: Update on Adjuvant Endocrine Therapy for Women With Hormone Receptor-Positive Breast Cancer. J Clin Oncol. 2010:28:3784-96. 